\title{
Comparison of dentinal and apical crack formation caused by four different nickel-titanium rotary and reciprocating systems in large and small canals
}

\author{
Xin ZHOU ${ }^{1,2}$, Shan JIANG $^{3}$, Xiao WANG ${ }^{1}$, Shuai WANG ${ }^{2}$, Xiaofei ZHU ${ }^{4}$ and Chengfei ZHANG ${ }^{2}$ \\ ${ }^{1}$ Department of Stomatology, Peking University Third Hospital, 49 Garden Road North, Haidian District, Beijing, 100191, China \\ ${ }^{2}$ Comprehensive Dental Care (Endodontics), Faculty of Dentistry, The University of Hong Kong, 34 Hospital Road, Sai Ying Pun, Hong Kong SAR, \\ China \\ ${ }^{3}$ Department of Endodontics and Operative Dentistry I, School and Hospital of Stomatology, Fujian Medical University, 246 Yangqiao Zhong Road, \\ Fuzhou, Fujian 350002, China \\ ${ }^{4}$ VIP Dental Service and Geriatric Dentistry, School and Hospital of Stomatology, Peking University, 22 Zhongguancun, Nandajie, Haidian District, \\ Beijing 100081, China \\ Corresponding author, Chengfei ZHANG; E-mail: zhangcf@hku.hk
}

\begin{abstract}
This study compared dentinal and apical crack formation after instrumentation with different nickel-titanium systems at two different working lengths (WL) in large and small canals. Two hundred and eighty human teeth were randomly distributed into two control and 12 experimental groups ( $n=20$ each). Large and small canals were instrumented by the WaveOne, Protaper Universal System (PTU), Twisted File (TF), or Twisted File Adaptive (TFA) at $1 \mathrm{~mm}$ shorter than canal length (CL-1 mm) or $1 \mathrm{~mm}$ beyond apical foreman $(\mathrm{CL}+1 \mathrm{~mm})$. Horizontal sections were microscopically observed to evaluate the dentinal cracks (only large canals). Scanning electron microscopy images were taken before and after instrumentation to assess apical cracks. All file types caused more apical cracks in small canals than in large canals regardless of the WL. During over-instrumentation $(\mathrm{WL}=\mathrm{CL}+1 \mathrm{~mm})$, the WaveOne and PTU groups developed significantly more dentinal cracks at the 6 and $9 \mathrm{~mm}$ sections than the TF and TFA groups.
\end{abstract}

Keywords: Dentinal crack, Apical crack, Twisted file adaptive, Nickel-titanium system, Scanning electron microscopy

\section{INTRODUCTION}

Eliminating infections and preventing re-infections are critical for the long-term success of root canal treatment ${ }^{1}$. Shaping the root canal system with a greater taper and larger apical foramen size are recommended, likely to remove more of the infected dentin and create space for the irrigants and antibacterial medicaments to eradicate bacteria ${ }^{2}$. Therefore, various nickel-titanium (NiTi) rotary and reciprocating files with a greater taper and larger apical diameter were developed ${ }^{3}$. Recent studies have shown that NiTi rotary and reciprocating files greatly improved the clinical outcomes and reduced the incidence of preparation errors ${ }^{4)}$. However, mechanical instrumentation with large taper files may remove excessive dentin, exert more stress on the canal wall, and generate cracks on the dentin and the apical surface, which could lead to vertical root fractures and even require tooth extraction ${ }^{5,6)}$.

Successful rotary and reciprocating canal preparation largely depends on an accurate determination of the canal dimensions, curvatures, and merging points using preoperative diagnostic analysis including radiographs and clinical evaluations ${ }^{7}$. Unfortunately, no consensus has emerged on how to best determine the width and taper for apical preparation. Inappropriate determination of working length (WL) and apical size are often unavoidable because of

Color figures can be viewed in the online issue, which is available at J-STAGE.

Received Jun 4, 2015: Accepted Jul 17, 2015

doi:10.4012/dmj.2015-197 JOI JST.JSTAGE/dmj/2015-197 undetectable, but critical variations in apical morphology, which may affect treatment outcome ${ }^{8}$. Studies using radiography, stereomicroscopy, and scanning electron microscopy have demonstrated that the frequency of deviation of the major foramen ranged from $34 \%$ to $92 \%$. The distance between the major foramen and the anatomical root apex ranged from 0.2 to $3.8 \mathrm{~mm}^{9-11}$. In clinical cases, there was a $20 \%$ to $89 \%$ chance for the file to protrude beyond the major apical foramen, which increases the risk of unintentional over-instrumentation and leads to problems such as postoperative pain, delayed apical healing, and apical cracks ${ }^{12-14)}$. Another controversial issue in endodontics is the final size to which the apical third should be enlarged ${ }^{4}$. Traditionally, clinicians enlarge the apical canal by three ISO-sizes greater than the initial file that binds at WL based on a tactile sense. This method is unreliable because tactile sensation of the apical file constricted might be from the interference in the coronal or middle portions of the root canal ${ }^{15}$. A misfit between the file shape and canal morphology is another reason why this concept for gauging the apical diameter is of questionable clinical value ${ }^{16)}$. Therefore, the complexity of root canal anatomy and apical variants should be individually considered when enlarging root canals to a case-specific taper and size ${ }^{17)}$.

Generally, root canals were classified into two categories: large canals, that typically possess large canal diameters in their coronal halves with apical diameters of $0.20-0.35 \mathrm{~mm}$ and relatively less curvature; 
and small canals that typically present narrow canal diameters in their coronal halves with apical diameters of $0.15-0.20 \mathrm{~mm}$ and slight to severe canal curvatures ${ }^{18)}$. It was suggested enlarging large canals to 0.1 taper and small canals to 0.06 taper. When preparing narrowly curved canals, more pronounced transportation was created $^{19)}$. Furthermore, the Protaper Universal System showed significantly higher peak torque and force magnitudes when used on small canals than on lager canals $^{20)}$. Obviously, the rotary and reciprocating NiTi files have more contact areas and cut more dentin in the small canals than in the large canals. This increased removal of canal wall dentin could hypothetically produce more pressure or stress on the root wall and subsequently more crack formation. A series of studies on dentinal and apical cracks initiation and propagation have been performed in vitro, concluding that rotary and reciprocating instruments contributed more to the root cracks than hand files ${ }^{4,15,21,22)}$. Clinically, WaveOne, Protaper Universal System (PTU), Twisted File (TF), and Twisted File Adaptive (TFA), performing better in root canal instrumentation, are now commonly applied worldwide. However, to date, no information available on assessment of the WaveOne, PTU, TF, and TFA system regarding formation of apical and dentinal cracks in both large and small canals.

The purpose of this study was to compare the incidence of crack formation on root canal dentin (only large canals) and the apical surface (both large and small canals) after instrumentation by four different NiTi rotary (PTU and TF) and reciprocating (WaveOne and TFA) file systems at two different WL.

\section{MATERIALS AND METHODS}

\section{Root selection and preparation}

This study was approved by the Ethics Committee of the Health Science Center, Peking University, and informed consent was obtained from all subjects involved in this study. Human mandibular premolars and mandibular molars that had been extracted for periodontal reasons were collected from the Dental Clinic of Peking University Third Hospital. Extracted teeth were immediately stored in purified filtered water until further use. All teeth were disinfected with iodine and $70 \%$ ethanol to avoid contamination. Teeth were then observed under a digital microscope (Leica M320 F12, Leica Microsystems, Wetzlar, Germany) at $\times 40$ magnification. Those that presented with endodontic treatment, open apices, or fracture lines were excluded. Radiographs were taken from the buccolingual and mesiodistal directions to confirm the presence of a single canal in the premolar teeth and a single mesiobuccal canal in the molar teeth.

Teeth crowns were removed at $2 \mathrm{~mm}$ above the proximal cementoenamel junction perpendicular to the long axis of the tooth with an electric saw machine (Miki Pulley, Kanagawa, Japan) cooled with water. Each root was coated with wet gauze and embedded in a plastic tube filled with silicone rubber in order to simulate periodontal tissue and maintain the humidity throughout the operation. The apical $2 \mathrm{~mm}$ of the root was exposed for intraoperative imaging. A size 10 stainless steel K-file (Dentsply Maillefer, Ballaigues, Switzerland) was introduced into the canals of all samples under the digital microscope at $\times 40$ magnification until the tip became visible at the apical foramen. The canal length (CL) of each sample was defined as the distance between the file tip and the coronal surface. If a size $20 \mathrm{~K}$-file inserted into the canals reached the apical constriction without resistance, we defined the canal as a large canal. Meanwhile, if the apical constriction could not be reached easily by a size $15 \mathrm{~K}$-file, the canal was defined as a small canal. Finally, 180 large canals in the premolars and 100 small canals in the molars were selected for the experiment. Next, each canal was enlarged with consecutive hand-use stainless steel K-files sized \#10, \#15 and \#20 to the CL (Dentsply Maillefer). The canals were irrigated with 2 $\mathrm{mL}$ of $1 \%$ sodium hypochlorite $(\mathrm{NaClO})$ using a syringe with a $27-\mathrm{G}$ needle between each file.

Samples were thoroughly flushed using a three-way syringe with distilled water under the digital microscope, placed in an auto drybox (Eureka, AD-101, TaiWan Dry Tech, Taipei, Taiwan) for $5 \mathrm{~min}$, and then spray-coated with gold (MSP-2S, Ixrf Systems, Japan). Images of the apical foramen area were taken at $\times 50$ and $\times 100$ magnifications as the baselines using scanning electron microscopy (SEM, SU1510, Hitachi, Tokyo, Japan).

\section{Experimental groups and instrumentation procedures}

The 180 large canals in the mandibular premolars were randomly assigned to nine groups of twenty teeth each. One group $(n=20)$ was left uninstrumented as a control. The other eight groups (20 specimens per group) were instrumented with one of the following four NiTi systems: WaveOne (WaveOne, Dentsply Maillefer), Protaper Universal System (PTU, Dentsply Maillefer), Twisted File (TF, SybronEndo, Orange, CA, USA), and Twisted File Adaptive (TFA, SybronEndo) at one of two different WLs: CL-1 $\mathrm{mm}$ or CL+1 $\mathrm{mm}$.

The 100 small mesiobuccal canals in the mandibular molars were randomly divided into five groups of twenty teeth each. One group $(n=20)$ was left uninstrumented as a control. The other four groups (20 specimens per group) were each instrumented with one of the same four file types at $\mathrm{WL}=\mathrm{CL}-1 \mathrm{~mm}$ or $\mathrm{WL}=\mathrm{CL}+1 \mathrm{~mm}$. The details of the instrumentation procedures are described below.

In the WaveOne groups, the WaveOne large file \#40.08 (Dentsply Maillefer) was used with their propriety motor in the "WaveOne All" mode.

In the PTU groups, the canals were filed using the Protaper Universal System (Dentsply Maillefer) in the sequence SX, S1, S2, F1, F2, and F3, and then F4 to obtain a final size of $0.4 \mathrm{~mm}$ in the apex. SX was used at two-thirds of the WL, S1 and S2 at the WL-1 mm, and then F1, F2, F3, and F4 at the WL.

In the $\mathrm{TF}$ groups, the Twisted File System (SybronEndo) was used in a 16:1 gear reduction handpiece at a constant rotation of $300 \mathrm{rpm}$. The 
sequence of files was \#25.08, \#25.06, \#30.06, and then \#40.04. \#25.08 was used at two thirds of the WL, and then \#25.06, \#30.06, and \#40.04 at the WL.

In the TFA groups, the TF Adaptive System (SybronEndo) was used with the same motor and handpiece as for the TF groups, but included the specialized Adaptive Motion Technology, which rotated clockwise and, depending on the load on the file, adapted and reversed to rotate counter-clockwise by coasting in a reciprocating motion. The sequence of files was \#25.08, \#30.06, and \#50.04, and \#30.06 and \#50.04 reached the WL.

Each NiTi system was used at a specific torque and speed-controlled motor according to each manufacturer's instructions. Each NiTi file was replaced after preparing 4 canals. The canals were irrigated with $2 \mathrm{~mL}$ of $1 \%$ sodium hypochlorite $(\mathrm{NaOCl})$, and a \#10 K-File was used to confirm the patency of the canal between each instrument. All root instrumentations were performed by single operator.

\section{Evaluation of dentinal and apical crack formation}

The incidence of crack formation was evaluated by assessing both dentinal cracks on the root canal wall and apical cracks on the apical surface. All the premolars were sectioned using an electric saw machine (Miki Pulley) cooled with water at 3,6, and $9 \mathrm{~mm}$ from the apex. The three sections from each sample were observed under the digital microscope at $\times 40$ magnification. The images were recorded and assessed for the presence of dentinal cracks by two blinded and previously calibrated examiners. Any cracks extending from the internal surface of the root canal to the external root surface were defined as dentinal cracks ${ }^{23}$. Two SEM images of the apical foramen area of each tooth were taken after instrumentation at $\mathrm{WL}=\mathrm{CL}-1 \mathrm{~mm}$ and $\mathrm{WL}=\mathrm{CL}+1 \mathrm{~mm}$. Images at $\times 50$ and $\times 100$ magnifications were recorded and assessed by two calibrated examiners. Any cracks near the apical foramen that were not present in the baseline image were defined as apical cracks ${ }^{22}$. The control group was treated by the same procedures of cleaning, drying, and SEM as the other groups, except for the instrumentation.

\section{Statistical analysis}

Using SPSS18.0 (SPSS, Chicago, IL, USA), Chi-square tests were used to compare the presence of dentinal cracks on the three sectioned levels in large canals and the presence of apical cracks around the apical foramen in large and small canals among the different WLs and file types. $p$-Values less than 0.05 were considered statistically significant.

\section{RESULTS}

\section{Dentinal cracks in large canals}

The numbers of teeth with cracks at the three sectioned levels separated by WL and file type are shown in Table 1. No cracks were found in either the control group or the TFA group. In large canals, where instrumentation was limited (WL $=\mathrm{CL}-1 \mathrm{~mm}$ ), the incidence of dentinal and apical cracks was not significantly different between the four experimental groups $(p>0.05)$. During overinstrumentation $(\mathrm{WL}=\mathrm{CL}+1 \mathrm{~mm})$, the WaveOne and PTU groups had more dentinal cracks at the 6 and 9 $\mathrm{mm}$ section levels from the apex than the TF and TFA groups $(p<0.05)$. Example dentinal cracks found at the 6 and $9 \mathrm{~mm}$ sections from the apex in a large canal overinstrumented by the WaveOne file \#40.08 are shown in Figs. 1a-c.

\section{Apical cracks in large and small canals}

The numbers of teeth with apical cracks at the different WLs in large and small canals are shown in Table 2. There were no cracks on the apical surface of either control group at the baseline assessment. All file type groups had more apical cracks in small canals than in large canals regardless of the WL, but that difference was not significant $(p>0.05)$. During over-instrumentation, the WaveOne, PTU, and TFA groups were significantly

Table 1 Numbers of teeth with dentinal cracks at the three sectioned levels in the experimental and control groups

\begin{tabular}{|c|c|c|c|c|c|c|c|}
\hline \multirow[b]{2}{*}{ Section level } & \multirow{2}{*}{$\begin{array}{c}\text { WL } \\
\text { cracks/n }\end{array}$} & \multirow{2}{*}{$\begin{array}{c}\text { Control } \\
\text { cracks/n }\end{array}$} & \multicolumn{4}{|c|}{ Experimental files } & \multirow{2}{*}{$\begin{array}{l}\text { Total } \\
\text { cracks }\end{array}$} \\
\hline & & & $\begin{array}{l}\text { WaveOne } \\
\text { cracks/n }\end{array}$ & $\begin{array}{c}\text { PTU } \\
\text { cracks/n }\end{array}$ & $\begin{array}{c}\mathrm{TF} \\
\text { cracks/n }\end{array}$ & $\begin{array}{c}\text { TFA } \\
\text { cracks/n }\end{array}$ & \\
\hline \multirow{2}{*}{$3 \mathrm{~mm}$} & $\mathrm{CL}-1 \mathrm{~mm}$ & $0 / 20$ & $1 / 20$ & $0 / 20$ & $0 / 20$ & $0 / 20$ & 1 \\
\hline & $\mathrm{CL}+1 \mathrm{~mm}$ & $0 / 20$ & $2 / 20$ & $2 / 20$ & $0 / 20$ & $0 / 20$ & 4 \\
\hline \multirow{2}{*}{$6 \mathrm{~mm}$} & $\mathrm{CL}-1 \mathrm{~mm}$ & $0 / 20$ & $1 / 20$ & $1 / 20$ & $1 / 20$ & $0 / 20$ & 3 \\
\hline & $\mathrm{CL}+1 \mathrm{~mm}$ & $0 / 20$ & $6 / 20$ & $4 / 20$ & $0 / 20$ & $0 / 20$ & 10 \\
\hline \multirow{2}{*}{$9 \mathrm{~mm}$} & $\mathrm{CL}-1 \mathrm{~mm}$ & $0 / 20$ & $1 / 20$ & $0 / 20$ & $0 / 20$ & $0 / 20$ & 1 \\
\hline & $\mathrm{CL}+1 \mathrm{~mm}$ & $0 / 20$ & $4 / 20$ & $6 / 20$ & $0 / 20$ & $0 / 20$ & 10 \\
\hline \multicolumn{2}{|c|}{ Total cracks } & 0 & 15 & 13 & 1 & 0 & 29 \\
\hline
\end{tabular}

CL: canal length; WL: working length; PTU: ProTaper Universal System; TF: Twisted File System; TFA: Twisted File Adaptive System. 


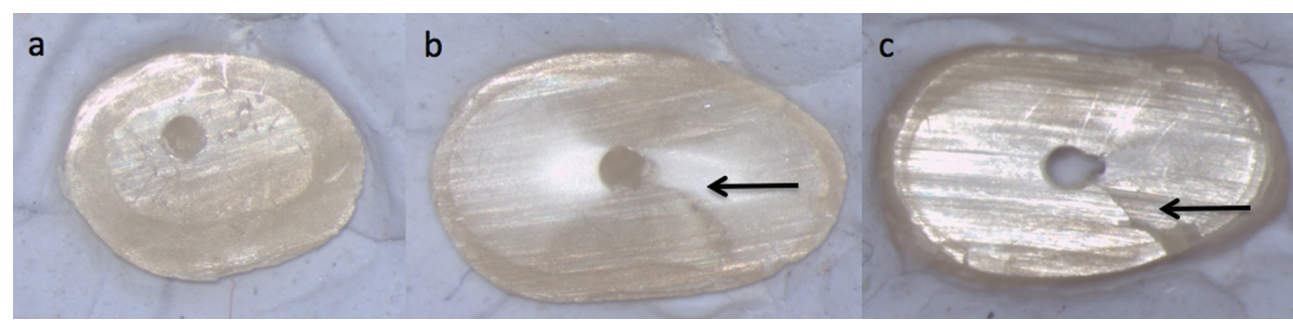

Fig. 1 Microscopy images of an example dentinal crack in a large canal over-instrumented with the WaveOne.

(a) No crack was found in the section $3 \mathrm{~mm}$ from the apex after instrumentation. Obvious cracks were found in the (b) $6 \mathrm{~mm}$ and (c) $9 \mathrm{~mm}$ sections.

Table 2 Numbers of teeth with apical cracks at different working lengths in the experimental and control groups

\begin{tabular}{|c|c|c|c|c|c|c|c|}
\hline \multirow[b]{2}{*}{ Teeth } & \multirow{2}{*}{$\begin{array}{c}\text { WL } \\
\text { cracks/n }\end{array}$} & \multirow{2}{*}{$\begin{array}{c}\text { Control } \\
\text { cracks } / n\end{array}$} & \multicolumn{4}{|c|}{ Experimental files } & \multirow{2}{*}{$\begin{array}{l}\text { Total } \\
\text { cracks }\end{array}$} \\
\hline & & & $\begin{array}{l}\text { WaveOne } \\
\text { cracks/n }\end{array}$ & $\begin{array}{c}\mathrm{PT} \\
\text { cracks/n }\end{array}$ & $\begin{array}{c}\mathrm{TF} \\
\text { cracks/n }\end{array}$ & $\begin{array}{c}\text { TFA } \\
\text { cracks/n }\end{array}$ & \\
\hline \multirow{3}{*}{ Large canals } & baseline & $0 / 20$ & $0 / 40$ & $0 / 40$ & $0 / 40$ & $0 / 40$ & 0 \\
\hline & $\mathrm{CL}-1 \mathrm{~mm}$ & $0 / 20$ & $2 / 20$ & $1 / 20$ & $1 / 20$ & $1 / 20$ & 5 \\
\hline & $\mathrm{CL}+1 \mathrm{~mm}$ & $0 / 20$ & $3 / 20$ & $5 / 20$ & $2 / 20$ & $2 / 20$ & 12 \\
\hline \multirow{3}{*}{ small canals } & baseline & $0 / 20$ & $0 / 20$ & $0 / 20$ & $0 / 20$ & $0 / 20$ & 0 \\
\hline & $\mathrm{CL}-1 \mathrm{~mm}$ & $0 / 20$ & $1 / 20$ & $3 / 20$ & $1 / 20$ & $2 / 20$ & 7 \\
\hline & $\mathrm{CL}+1 \mathrm{~mm}$ & $0 / 20$ & $8 / 20$ & $6 / 20$ & $4 / 20$ & $5 / 20$ & 23 \\
\hline \multicolumn{2}{|c|}{ Total cracks } & 0 & 14 & 15 & 8 & 10 & 47 \\
\hline
\end{tabular}

CL: canal length; WL: working length; PTU: ProTaper Universal System; TF: Twisted File System; TFA: Twisted File Adaptive System.
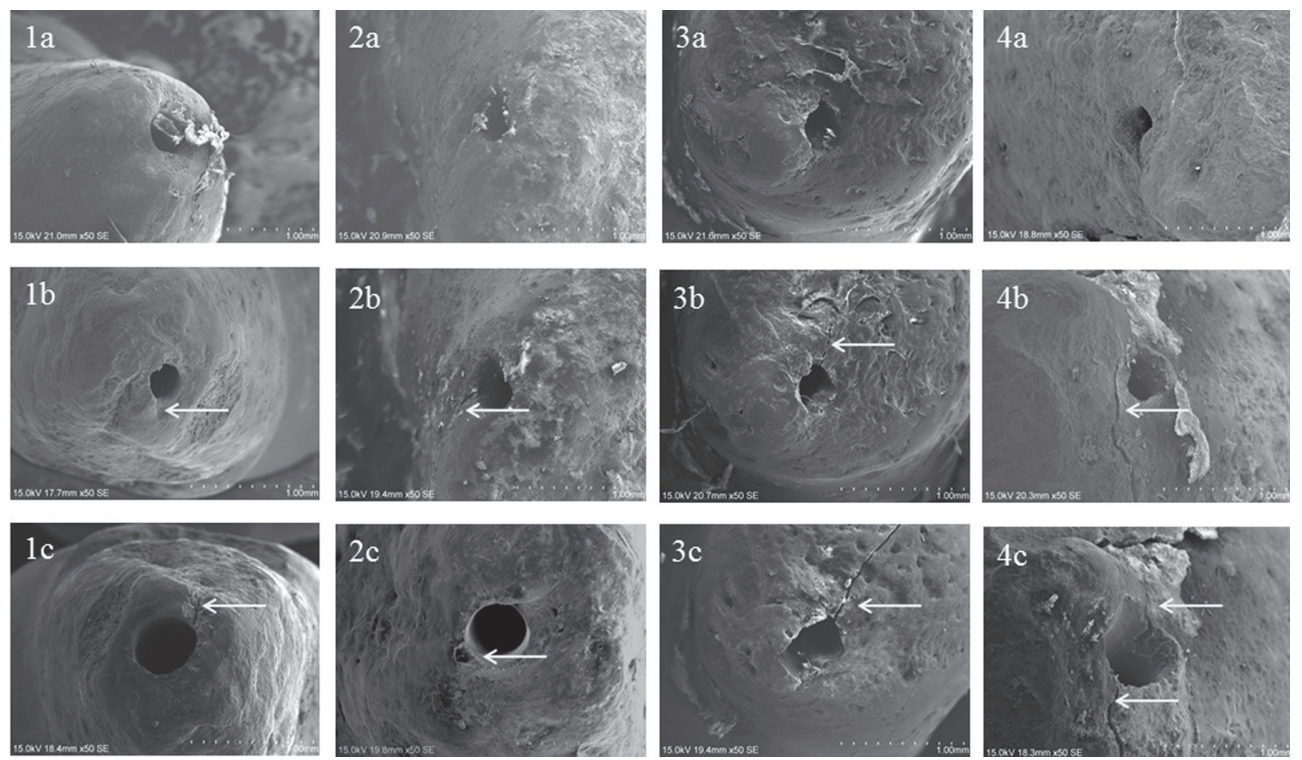
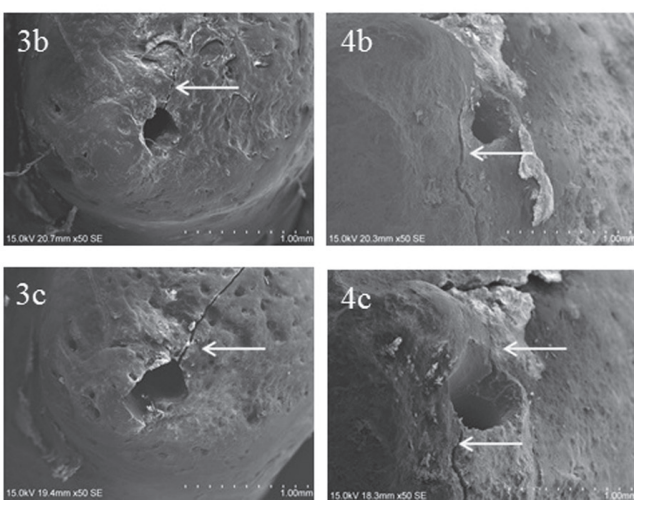

Fig. 2 SEM images of an example apical crack in a small canal over-instrumented with the WaveOne (Column 1), PTU (Column 2), TF (Column 3), and TFA (Column 4).

(a) Before instrumentation, (b) After instrumentation at WL=CL-1 mm, (c) After overinstrumentation to $\mathrm{WL}=\mathrm{CL}+1 \mathrm{~mm}$. White arrow pointing to the crack. 
different than the control group $(p<0.05)$, whereas there was no significant difference among file types at $\mathrm{WL}=\mathrm{CL}-1 \mathrm{~mm}$ or $\mathrm{WL}=\mathrm{CL}+1 \mathrm{~mm}(p>0.05)$. In small canals, the WaveOne group showed more apical cracks when instrumented at WL=CL+1 $\mathrm{mm}$ than at WL $=\mathrm{CL}-1$ $\mathrm{mm}(p<0.05)$. SEM images of apical cracks found in a small canal by WaveOne, PTU, TF, and TFA filesare shown in Fig. 2.

\section{DISCUSSION}

A series of studies on the incidence of dentinal and apical cracks demonstrated a correlation between crack formation and file type, instrumentation technique, WL, and apical foramen position ${ }^{15,21,24)}$. The assessment methods used in such studies are typically photographing root sections or the apical surface using stereoscopic microscopy ${ }^{16)}$ and digital microscopy ${ }^{21)}$, with a limited number using $\mathrm{SEM}^{25)}$. SEM provides distinct images of dentin sections and the apical surface, allowing detailed observation of microcracks ${ }^{25}$. In the present study, digital microscopy was used to observe dentinal cracks on cut sections, and SEM was used to assess the presence of cracks formed on the apical surface. The absence of cracks in the control group, which was treated with the same cutting, drying, spray-coating, and SEM observations as the experimental groups, confirmed that the preparation procedures for the sectioning and SEM examination did not induce crack formation themselves.

Studies by Toure et al. ${ }^{5}$ and Yoldas et al. ${ }^{14)}$ indicated that instrumentation with hand files did not cause dentinal cracks. Rotary and reciprocating NiTi instrumentation induced more root cracks than hand files, which were attributed to the NiTi instrument properties and motion ${ }^{15,21)}$. When the root canals were enlarged by hand with K-files from \#10 to \#20 in our control group, no cracks were observed. Based on studies from our group and others, we conclude that the minimal intervention of a root canal system with the hand K-files from \#10 to \#20 maintains the integrity of the root canals ${ }^{6)}$. However, minimal preparation of root canal systems cannot eliminate infection entirely, making hermetic obturation difficult and reducing the chance of a successful outcome ${ }^{26)}$.

The PTU and TF systems are currently popular, though both generate higher incidences of cracks than hand files ${ }^{8,14)}$. The WaveOne and TFA systems are relatively new products that shape root canals with a reciprocating movement, which is different from a rotary motion. The hypothesis behind their design was that reciprocal motion could relieve stress on the instruments, and therefore reduce the risk of cyclic fatigue caused by tension and compression. At the same time, the reciprocal motion, which works in a counterclockwise direction when cutting dentin and in a clockwise direction when the instrument is being released, reduces excessive pressure on the root canal walls $^{27,28)}$.

Within the limitations of this study, we found that when root canal instrumentation was limited
(WL $=\mathrm{CL}-1 \mathrm{~mm}$ ), more dentinal and apical cracks were observed in the four experimental groups than in the controls, but the differences between the experimental and control groups were not significant. However, when over-instrumentation was performed (WL=CL $+1 \mathrm{~mm}$ ), the WaveOne and PTU systems caused significantly more dentinal and apical cracks than the other two groups in the upper two-thirds of the root canal. The largest taper of the files at WL in the different groups were \#40.08 in WaveOne, \#30.09 in PTU, \#30.06 in TF, and \#30.06 in TFA. The files with larger tapers also had larger diameters in the upper portion such as the WaveOne \#40.08 and PT \#30.09, which increased the contact areas with the canal wall, removed more dentin, and generated more pressure on root canal wall. Yoldas et $a l .{ }^{14)}$ and Milani et $a l .{ }^{23)}$ also reported that Protaper rotary files were associated with significantly more microcracks than other NiTi instruments because of their larger cross-sections, greater stiffness, and higher levels of torque and bending force ${ }^{29)}$.

The feature of TFA file, such as moderate taper, higher flexibility, and special motion ${ }^{30)}$, might contribute to better prevention of both dentinal and apical cracks. In specific, TFA file rotated clockwise and, depending on the load on the file, adapted and reversed to rotate counter-clockwise by coasting in a reciprocating motion, which might reduce the continuous pressure on the root canal wall, further reducing the likelihood of cracking.

Clinically, unintentional protrusion of the file beyond the major apical foramen occurs in 20 to $89 \%$ of cases ${ }^{14)}$. Therefore, over-instrumentation is nearly unavoidable. Working at $1 \mathrm{~mm}$ short of the apical foramen produced fewer cracks in the apical region than over-instrumentation $^{31}$. In the present study, we found that all types of rotary and reciprocating NiTi systems used cause cracks on the apical surface regardless of the WL, and the number of cracks clearly increased when instrumentation was taken beyond the apical foramen. When the files go beyond the apical foramen, their flexibility is critical to avoid apical crack formation, as a higher flexibility allows the files to easily follow the apical curvature ${ }^{32}$, while greater stiffness increase the levels of torque and bending force ${ }^{29)}$. The WaveOne file consistently caused more apical cracks in small canals than in large canals in the present study. One possible explanation for this is that a greater number of repetitive pecking times is required in order to instrument a small canal to a large apical taper and diameter, which cuts more volume of dentin, resulting in more apical cracks ${ }^{33)}$. Another is that the lower flexibility of the WaveOne may have exerted a higher bending force towards the apical foramen walls.

Although no consensus has been reached on the best apical size for apical preparation, apical enlargement to size \#40.04 has been suggested as a good balance between the preservation of the tooth structure and the maximum volume of irrigation in the apical third ${ }^{2)}$. Therefore, in the present study, we instrumented both the small canal and large canal groups to apical size 40 (except TFA, which was sized to 50), and assessed 
whether preparing large and small canals to the same file size affects the incidence of root cracks. Intuitively, the incidence of crack formation in mandibular molars with a single, small mesiobuccal canal should be higher than in premolars with large canals. Overinstrumentation of small canals with the WaveOne file produced significantly more apical cracks than when working short of the WL. Adorno et al. ${ }^{34)}$ reported an even higher incidence of cracks in mandibular incisors after NiTi rotary instrumentation than found here, ranging from $25 \%$ to $67 \%$. The mandibular incisors used by Adorno et al. ${ }^{34)}$ may have contained even smaller canals than the mesiobuccal canals of the lower molars used in our study. Another difference is that we enlarged the mesiobuccal canals to size 20 with a hand K-file before using the NiTi systems, reducing the constriction of all canals in the experiment. Although no ideal methods for determining the morphology of root canal systems have yet been described, clinicians must preoperatively assess the taper of canals and the size of the apical foramen using periapical radiography, micro-computed tomography, an apex locater, or even tactile sensation. Once canals are labeled as small, large-tapered and stiff NiTi systems should not be used in order to reduce the incidence of crack formation.

\section{CONCLUSION}

Rotary and reciprocating NiTi systems are more likely to induce dentinal and apical cracks when overinstrumenting root canals. The WaveOne system with larger size and taper files may not be suitable for instrumenting small canals.

\section{ACKNOWLEDGMENT}

The authors deny any conflicts of interest related to this study.

\section{REFERENCES}

1) Peters LB, van Winkelhoff AJ, Buijs JF, Wesselink PR. Effects of instrumentation, irrigation and dressing with calcium hydroxide on infection in pulpless teeth with periapical bone lesions. Int Endod J 2002; 35: 13-21.

2) Brunson M, Heilborn C, Johnson DJ, Cohenca N. Effect of apical preparation size and preparation taper on irrigant volume delivered by using negative pressure irrigation system. J Endod 2010; 36: 721-724.

3) Iqbal MK, Maggiore F, Suh B, Edwards KR, Kang J, Kim $\mathrm{S}$. Comparison of apical transportation in four Ni-Ti rotary instrumentation techniques. J Endod 2003; 29: 587-591.

4) Hülsmann M, Peters OA, Dummer PMH. Mechanical preparation of root canals: Shaping goals, techniques and means. Endod Topics 2005; 10: 30-76.

5) Touré B, Faye B, Kane AW, Lo CM, Niang B, Boucher Y. Analysis of reasons for extraction of endodontically treated teeth: A prospective study. J Endod 2011; 37: 1512-1515.

6) Bier CA, Shemesh H, Tanomaru-Filho M, Wesselink PR, Wu MK. Theability of different nickel-titanium rotary instruments to induce dentinal damage during canal preparation. J Endod 2009; 35: 236-238.

7) Janner SF, Jeger FB, Lussi A, Bornstein MM. Precision of endodontic working length measurements: A pilot investigation comparing cone-beam computed tomography scanning with standard measurement techniques. J Endod 2011; 37: 1046-1051.

8) Saini HR, Tewari S, Sangwan P, Duhan J, Gupta A. Effect of different apical preparation sizes on outcome of primary endodontic treatment: a randomized controlled trial. J Endod 2012; 38: 1309-1315.

9) Marroquin BB, El-Sayed MA, Willershausen-Zonnchen B. Morphology of the physiological foramen: I. Maxillary and mandibular molars. J Endod 2004; 30: 321-328.

10) Martos J, Ferrer-Luque CM, González-Rodríguez MP, Castro LA. Topographical evaluation of the major apical foramen in permanent human teeth. Int Endod J 2009; 42: 329-334.

11) Kerekes K, Tronstad L. Morphometric observations on root canals of human anterior teeth. J Endod 1977; 3: 24-29.

12) Vieyra JP, Acosta J, Mondaca JM. Comparison of working length determination with radiographs and two electronic apex locators. Int Endod J 2010; 43: 16-20.

13) Stöber EK, Duran-Sindreu F, Mercadé M, Vera J, Bueno R, Roig M. An evaluation of root ZX and iPex apex locators: An in vivo study. J Endod 2011; 37: 608-610.

14) Yoldas O, Yilmaz S, Atakan G, Kuden C, Kasan Z. Dentinal microcrack formation during root canal preparations by different NiTi rotary instruments and the self-adjusting file. J Endod 2012; 38: 232-235.

15) Wu MK, Barkis D, Roris A, Wesselink PR. Does the first file to bind correspond to the diameter of the canal in the apical region? Int Endod J 2002; 35: 264-267.

16) Paque F, Zehnder M, Marending M. Apical fit of initial K-files in maxillary molars assessed by micro-computed tomography. Int Endod J 2010; 43: 328-335.

17) Vertucci F. Root canal morphology and its relationship to endodontic procedures. Endod Topics 2005; 10: 3-29.

18) Buchanan LS. The standardized-taper root canal preparation -Part 2. GT file selection and safe handpiece-driven file use. Int Endod J 2001; 34: 63-71.

19) Peters OA, Schonenberger K, Laib A. Effects of four Ni-Ti preparation techniques on root canal geometry assessed by micro computed tomography. Int Endod J 2001; 34: 221-230.

20) Arias A, Singh R, Peters OA. Torque and force induced by ProTaper universal and ProTaper next during shaping of large and small root canals in extracted teeth. J Endod 2014; 40: 973-976.

21) Liu R, Kaiwar A, Shemesh H, Wesselink PR, Hou B, Wu MK. Incidence of apical root cracks and apical dentinal detachments after canal preparation with hand and rotary files at different instrumentation lengths. J Endod 2013; 39: 129-132.

22) Adorno CG, Yoshioka T, Suda H. The effect of working length and root canal preparation technique on crack development in the apical root canal wall. Int Endod J 2010; 43: 321-327.

23) Milani AS, Froughreyhani M, Rahimi S, Jafarabadi MA, Paksefat S. The effect of root canal preparation on the development of dentin cracks. Iran Endod J 2012; 7: 177182.

24) Kim HC, Lee MH, Yum J, Versluis A, Lee CJ, Kim BM. Potential relationship between design of nickel-titanium rotary instruments and vertical root fracture. J Endod 2010; 36: 1195-1199.

25) von Arx T, Kunz R, Schneider AC, Bürqin W, Lussi A. Detection of dentinal cracks after root-end resection: An ex vivo study comparing microscopy and endoscopy with scanning electron microscopy. J Endod 2010; 36: 1563-1568.

26) de Gregorio C, Arias A, Navarrete N, Del Rio V, Oltra E, Cohenca N. Effect of apical size and taper on volume of irrigant delivered at working length with apical negative pressure at different root curvatures. J Endod 2013; 39: 119124. 
27) De-Deus G, Brandão MC, Barino B, Di Giorgi K, Fidel RA, Luna AS. Assessment of apically extruded debris produced by the single-file ProTaper F2 technique under reciprocating movement. Oral Surg Oral Med Oral Pathol Oral Radiol Endod 2010; 110: 390-394.

28) Varela-Patiño P, Ibañez-Párraga A, Rivas-Mundiña B, Cantatore G, Otero XL, Martin-Biedma B. Alternating versus continuous rotation: A comparative study of the effect on instrument life. J Endod 2010; 36: 157-159.

29) Arbab-Chirani R, Chevalier V, Arbab-Chirani S, Calloch $\mathrm{S}$. Comparative analysis of torsional and bending behavior through finite-element models of $5 \mathrm{Ni}-\mathrm{Ti}$ endodontic instruments. Oral Surg Oral Med Oral Pathol Oral Radiol Endod 2011; 111: 115-121.

30) West JD. Introduction of a new rotary endodontic system: progressively tapering files. Dent Today 2001; 20: 50-52, 5457.

31) Adorno CG, Yoshioka T, Suda H. The effect of root preparation technique and instrumentation length on the development of apical root cracks. J Endod 2009; 35: 389-392.

32) Lim KC, Webber J. The validity of simulated root canals for the investigation of the prepared root canal shape. Int Endod J 1985; 18: 240-246.

33) Jeon HJ, Paranjpe A, Ha JH, Kim E, Lee W, Kim HC. Apical enlargement according to different pecking times at working length using reciprocating files. J Endod 2014; 40: 281-284.

34) Adorno CG, Yoshioka T, Suda H. Crack initiation on the apical root surface caused by three different nickel-titanium rotary files at different working lengths. J Endod 2011; 37: 522-525. 